Скопје, Македонија

\title{
SOME INEQUALITIES FOR THE ČEBYŠEV FUNCTIONAL AND GENERAL FOUR-POINT QUADRATURE FORMULAE OF
} EULER TYPE

\author{
M. KLARIČIĆ BAKULA, J. PEČARIĆ, M. RIBIČIĆ PENAVA, AND A. VUKELIĆ
}

\begin{abstract}
We use inequalities for the Čebyšev functional in terms of the first derivative (see [5]), for some new bounds for the remainder of four-point quadrature formulae of Euler type and its generalizations for Euler BullenSimpson's 3/8 formula. As special cases, we consider some new bounds for Euler Simpson's 3/8 formula, Euler Simpson's formula and Euler Gauss 2point formula.
\end{abstract}

\section{INTRODUCTION}

Let $x \in(0,1 / 2]$ and $f:[0,1] \rightarrow \mathbb{R}$ be such that $f^{(2 n+1)}$ is continuous of bounded variation on $[0,1]$ for some $n \geq 0$. In [6], the following formula is obtained:

$$
\begin{aligned}
\int_{0}^{1} f(t) d t-(1 / 2-A(x))[f(0) & +f(1)]-A(x)[f(x)+f(1-x)]+T_{2 n}(x) \\
& =\frac{1}{(2 n+2) !} \int_{0}^{1} F_{2 n+2}(x, t) d f^{(2 n+1)}(t),
\end{aligned}
$$

where, for $t \in \mathbb{R}$,

$$
\begin{aligned}
& T_{2 n}(x)=\sum_{k=2}^{2 n} \frac{1}{k !} G_{k}(x, 0)\left[f^{(k-1)}(1)-f^{(k-1)}(0)\right], \\
& G_{k}(x, t)=[1-2 A(x)] B_{k}^{*}(1-t)+A(x)\left[B_{k}^{*}(x-t)+B_{k}^{*}(1-x-t)\right], \quad k \geq 1 \\
& F_{k}(x, t)=G_{k}(x, t)-G_{k}(x, 0), \quad k \geq 2 .
\end{aligned}
$$

The functions $B_{k}(t)$ are the Bernoulli polynomials, $B_{k}=B_{k}(0)$ are the Bernoulli numbers, and $B_{k}^{*}(t), k \geq 0$, are periodic functions of period 1 , related to the Bernoulli polynomials as

$$
B_{k}^{*}(t)=B_{k}(t), 0 \leq t<1 \text { and } B_{k}^{*}(t+1)=B_{k}^{*}(t), t \in \mathbb{R} .
$$

2010 Mathematics Subject Classification. Primary: 26D15 Secondary: 26D20, 26D99.

Key words and phrases. Čebyšev functional, general four-point quadrature formulae of Euler type, Euler Bullen-Simpson's 3/8 formula, Euler Simpson's 3/8 formula, Euler Simpson's formula, Euler Gauss 2-point formula. 
The Bernoulli polynomials $B_{k}(t), k \geq 0$ are uniquely determined by the following identities

$$
B_{k}^{\prime}(t)=k B_{k-1}(t), k \geq 1 ; B_{0}(t)=1, B_{k}(t+1)-B_{k}(t)=k t^{k-1}, k \geq 0 .
$$

For some further details on the Bernoulli polynomials and the Bernoulli numbers see for example [1] or [3]. We have that $B_{0}^{*}(t)=1$ and $B_{1}^{*}(t)$ is a discontinuous function with a jump of -1 at each integer. It follows that $B_{k}(1)=B_{k}(0)=B_{k}$ for $k \geq 2$, so that $B_{k}^{*}(t)$ are continuous functions for $k \geq 2$. We get

$$
B_{k}^{* \prime}(t)=k B_{k-1}^{*}(t), k \geq 1
$$

for every $t \in \mathbb{R}$ when $k \geq 3$, and for every $t \in \mathbb{R} \backslash \mathbb{Z}$ when $k=1,2$.

If one wants to obtain from (1.1) the quadrature formula with the maximum degree of exactness (if values of derivatives at the end points are not to be included in the quadrature, then it is equal to 3$)$, a condition $G_{2}(x, 0)=0$ has to be imposed. In this way we get:

$$
A(x)=-\frac{B_{2}}{2\left(B_{2}(x)-B_{2}\right)}=\frac{1}{12 x(1-x)} .
$$

Formula (1.1) now becomes:

$$
\int_{0}^{1} f(t) d t-Q(0, x, 1-x, 1)+T_{2 n}^{Q 4}(x)=\frac{1}{(2 n+2) !} \int_{0}^{1} F_{2 n+2}^{Q 4}(x, t) d f^{(2 n+1)}(t),
$$

where

$$
\begin{gathered}
Q(0, x, 1-x, 1)=\frac{1}{12 x(1-x)}\left[-6 B_{2}(x) f(0)+f(x)+f(1-x)-6 B_{2}(x) f(1)\right] \\
T_{2 n}^{Q 4}(x)=\sum_{k=2}^{n} \frac{1}{(2 k) !} G_{2 k}^{Q 4}(x, 0)\left[f^{(2 k-1)}(1)-f^{(2 k-1)}(0)\right] \\
G_{k}^{Q 4}(x, t)=\frac{1}{12 x(1-x)}\left[B_{k}^{*}(x-t)-12 B_{2}(x) \cdot B_{k}^{*}(1-t)+B_{k}^{*}(1-x-t)\right] \\
F_{k}^{Q 4}(x, t)=G_{k}^{Q 4}(x, t)-G_{k}^{Q 4}(x, 0), \quad k \geq 2 .
\end{gathered}
$$

Assuming $f^{(2 n-1)}$ is continuous of bounded variation on $[0,1]$ for some $n \geq 1$, then we get:

$$
\int_{0}^{1} f(t) d t-Q(0, x, 1-x, 1)+T_{2 n}^{Q 4}(x)=\frac{1}{(2 n) !} \int_{0}^{1} G_{2 n}^{Q 4}(x, t) d f^{(2 n-1)}(t),
$$

while assuming $f^{(2 n)}$ fulfills the same condition for some $n \geq 0$, we get:

$$
\int_{0}^{1} f(t) d t-Q(0, x, 1-x, 1)+T_{2 n}^{Q 4}(x)=\frac{1}{(2 n+1) !} \int_{0}^{1} G_{2 n+1}^{Q 4}(x, t) d f^{(2 n)}(t) .
$$

More about quadrature formulae and error estimations (from the point of view of inequality theory) can be found in monographs [2] and [7]. 
For two Lebesgue integrable functions $f, g:[a, b] \rightarrow \mathbb{R}$, consider the Čebyšev functional:

$$
T(f, g):=\frac{1}{b-a} \int_{a}^{b} f(t) g(t) d t-\frac{1}{b-a} \int_{a}^{b} f(t) d t \cdot \frac{1}{b-a} \int_{a}^{b} g(t) d t .
$$

In [5] the authors proved the following theorems:

Theorem 1. Let $f, g:[a, b] \rightarrow \mathbb{R}$ be two absolutely continuous functions on $[a, b]$ with

$$
(\cdot-a)(b-\cdot)\left(f^{\prime}\right)^{2},(\cdot-a)(b-\cdot)\left(g^{\prime}\right)^{2} \in L[a, b] .
$$

Then we have the inequality

$$
\begin{aligned}
|T(f, g)| \leq & \frac{1}{\sqrt{2}}[T(f, f)]^{\frac{1}{2}} \frac{1}{\sqrt{b-a}}\left(\int_{a}^{b}(x-a)(b-x)\left[g^{\prime}(x)\right]^{2} d x\right)^{\frac{1}{2}} \\
\leq & \frac{1}{2(b-a)}\left(\int_{a}^{b}(x-a)(b-x)\left[f^{\prime}(x)\right]^{2} d x\right)^{\frac{1}{2}} \\
& \times\left(\int_{a}^{b}(x-a)(b-x)\left[g^{\prime}(x)\right]^{2} d x\right)^{\frac{1}{2}} .
\end{aligned}
$$

The constant $\frac{1}{\sqrt{2}}$ and $\frac{1}{2}$ are best possible in (1.12).

Theorem 2. Assume that $g:[a, b] \rightarrow \mathbb{R}$ is monotonic nondecreasing on $[a, b]$ and $f:[a, b] \rightarrow \mathbb{R}$ is absolutely continuous with $f^{\prime} \in L_{\infty}[a, b]$. Then we have the inequality

$$
|T(f, g)| \leq \frac{1}{2(b-a)}\left\|f^{\prime}\right\|_{\infty} \int_{a}^{b}(x-a)(b-x) d g(x) .
$$

The constant $\frac{1}{2}$ is best possible.

In this paper we will use the above theorems to get some new bounds for the remainders of general four-point formulae (1.9) and (1.10). Applications for Euler Bullen-Simpson's $3 / 8$ formula are also proved. As special cases, some new bounds for Euler Simpson's $3 / 8$ formula, Euler Simpson's formula and Euler Gauss 2-point formula are considered.

\section{Applications for the General Four-point formulae of Euler type}

Using Theorem 1 for identities (1.9) and (1.10) we get the following Grüss type inequalities:

Theorem 3. Let $f:[0,1] \rightarrow \mathbb{R}$ be such that $f^{(2 n)}$ is absolutely continuous for some $n \geq 1$ and $\left(f^{(2 n+1)}\right)^{2} \in L_{1}[0,1]$. Then for $x \in(0,1 / 2]$ we have

$$
\int_{0}^{1} f(t) d t-Q(0, x, 1-x, 1)+T_{2 n}^{Q 4}(x)=T G_{2 n}(f),
$$


and the remainder $T G_{2 n}(f)$ satisfies the estimations

$$
\begin{aligned}
& \left|T G_{2 n}(f)\right| \leq \\
& \frac{1}{12 x(1-x)}\left[\frac { 1 } { ( 4 n ) ! } \left(-B_{4 n}-B_{4 n}(1-2 x)+24 B_{2}(x) B_{4 n}(x)\right.\right. \\
& \left.\left.-72 B_{2}^{2}(x) B_{4 n}\right)\right]^{\frac{1}{2}} \times\left(\int_{0}^{1} t(1-t)\left[f^{(2 n+1)}(t)\right]^{2} d t\right)^{\frac{1}{2}} .
\end{aligned}
$$

For $f:[0,1] \rightarrow \mathbb{R}$ such that $f^{(2 n+1)}$ is absolutely continuous for some $n \geq 0$ and $\left(f^{(2 n+2)}\right)^{2} \in L_{1}[0,1]$ we have

$$
\int_{0}^{1} f(t) d t-Q(0, x, 1-x, 1)+T_{2 n}^{Q 4}(x)=T G_{2 n+1}(f),
$$

and the remainder $T G_{2 n+1}(f)$ satisfies the estimations

$$
\begin{aligned}
& \left|T G_{2 n+1}(f)\right| \leq \\
& \frac{1}{12 x(1-x)}\left[\frac { 1 } { ( 4 n + 2 ) ! } \left(B_{4 n+2}+B_{4 n+2}(1-2 x)-24 B_{2}(x) B_{4 n+2}(x)\right.\right. \\
& \left.\left.+72 B_{2}^{2}(x) B_{4 n+2}\right)\right]^{\frac{1}{2}} \times\left(\int_{0}^{1} t(1-t)\left[f^{(2 n+2)}(t)\right]^{2} d t\right)^{\frac{1}{2}} .
\end{aligned}
$$

Proof. If we apply Theorem 1 for $f \rightarrow G_{k}^{Q 4}, g \rightarrow f^{(k)}$, we deduce

$$
\begin{aligned}
& \left|\int_{0}^{1} G_{k}^{Q 4}(x, t) f^{(k)}(t) d t-\int_{0}^{1} G_{k}^{Q 4}(x, t) d t \cdot \int_{0}^{1} f^{(k)}(t) d t\right| \\
\leq & \frac{1}{\sqrt{2}}\left[T\left(G_{k}^{Q 4}(x, \cdot), G_{k}^{Q 4}(x, \cdot)\right)\right]^{\frac{1}{2}} \times\left(\int_{0}^{1} t(1-t)\left[f^{(k+1)}(t)\right]^{2} d t\right)^{\frac{1}{2}}
\end{aligned}
$$

where

$$
T\left(G_{k}^{Q 4}(x, \cdot), G_{k}^{Q 4}(x, \cdot)\right)=\int_{0}^{1}\left[G_{k}^{Q 4}(x, t)\right]^{2} d t-\left[\int_{0}^{1} G_{k}^{Q 4}(x, t) d t\right]^{2} .
$$

By easy calculation we get

$$
\int_{0}^{1} G_{k}^{Q 4}(x, t) d t=0
$$

and using integration by part we have

$$
\begin{aligned}
& \int_{0}^{1}\left(G_{k}^{Q 4}(x, t)\right)^{2} d t \\
= & (-1)^{k-1} \frac{k(k-1) \ldots 2}{(k+1)(k+2) \ldots(2 k-1)}\left[\int_{0}^{1} G_{1}^{Q 4}(x, t) G_{2 k-1}^{Q 4}(x, t) d t\right] \\
= & \frac{(-1)^{k-1}}{12 x(1-x)} \frac{(k !)^{2}}{(2 k) !} \\
\times & {\left[12 x(1-x) \int_{0}^{1} G_{2 k}^{Q 4}(x, t) d t+G_{2 k}^{Q 4}(x, x)+G_{2 k}^{Q 4}(x, 1-x)-12 B_{2}(x) G_{2 k}(x, 0)\right] }
\end{aligned}
$$


ČEBYŠEV FUNCTIONAL AND GENERAL FOUR-POINT QUADRATURE FORMULAE 73

$$
=\frac{(-1)^{k-1}}{144 x^{2}(1-x)^{2}} \frac{(k !)^{2}}{(2 k) !}\left[2 B_{2 k}+2 B_{2 k}(1-2 x)-48 B_{2}(x) B_{2 k}(x)+144 B_{2}^{2}(x) B_{2 k}\right] .
$$

If we put $k=2 n$ using (1.9) and (2.5), we deduce the representation (2.1) and the bound (2.2). For $k=2 n+1$ using (1.10) and (2.5), we deduce the representation (2.3) and the bound (2.4).

Remark 2.1: Because of (1.8) we get

$$
\int_{0}^{1} F_{k}^{Q 4}(x, t) d t=\int_{0}^{1} G_{k}^{Q 4}(x, t) d t-\int_{0}^{1} G_{k}^{Q 4}(x, 0) d t=-G_{k}^{Q 4}(x, 0),
$$

and also

$$
\begin{aligned}
\int_{0}^{1}\left[F_{k}^{Q 4}(x, t)\right]^{2} d t & =\int_{0}^{1}\left[G_{k}^{Q 4}(x, t)\right]^{2} d t-2 G_{k}^{Q 4}(x, 0) \int_{0}^{1} G_{k}^{Q 4}(x, t) d t \\
& +\left[G_{k}^{Q 4}(x, 0)\right]^{2}
\end{aligned}
$$

So, if we put $k=2 n+2$ in the proof of above theorem, using (1.4) similar as in (2.5) (with $n \leftrightarrow n+1$ ), we deduce the representation (2.1) and the bound (2.2), too.

Corollary 3.1. Let $f:[0,1] \rightarrow \mathbb{R}$ be such that $f^{(2 n+1)}$ is absolutely continuous for some $n \geq 0,\left(f^{(2 n+2)}\right)^{2} \in L_{1}[0,1]$ and $f^{(2 n+1)} \geq 0$ on $[0,1]$. Then for $x \in$ $\left(0, \frac{1}{2}-\frac{\sqrt{3}}{6}\right]$ we have

$$
\begin{aligned}
& 0 \leq(-1)^{n}\left\{\int_{0}^{1} f(t) d t-Q(0, x, 1-x, 1)+T_{2 n}^{Q 4}(x)\right\} \leq \\
& \frac{1}{12 x(1-x)}\left[\frac { 1 } { ( 4 n + 2 ) ! } \left(B_{4 n+2}+B_{4 n+2}(1-2 x)-24 B_{2}(x) B_{4 n+2}(x)\right.\right. \\
& \left.\left.+72 B_{2}^{2}(x) B_{4 n+2}\right)\right]^{\frac{1}{2}} \times\left(\int_{0}^{1} t(1-t)\left[f^{(2 n+2)}(t)\right]^{2} d t\right)^{\frac{1}{2}}
\end{aligned}
$$

and for $x \in\left[\frac{1}{3}, \frac{1}{2}\right]$

$$
\begin{aligned}
& 0 \leq(-1)^{n+1}\left\{\int_{0}^{1} f(t) d t-Q(0, x, 1-x, 1)+T_{2 n}^{Q 4}(x)\right\} \leq \\
& \frac{1}{12 x(1-x)}\left[\frac { 1 } { ( 4 n + 2 ) ! } \left(B_{4 n+2}+B_{4 n+2}(1-2 x)-24 B_{2}(x) B_{4 n+2}(x)\right.\right. \\
& \left.\left.+72 B_{2}^{2}(x) B_{4 n+2}\right)\right]^{\frac{1}{2}} \times\left(\int_{0}^{1} t(1-t)\left[f^{(2 n+2)}(t)\right]^{2} d t\right)^{\frac{1}{2}}
\end{aligned}
$$

Proof. We are using Lemma 1 from [6].

If in Theorem 3 we choose $x=1 / 3,1 / 2,1 / 2-\sqrt{3} / 6$ we get inequality related to Euler Simpson's 3/8, Euler Simpson's and Euler Gauss 2-point formula: 
Corollary 3.2. Let $f:[0,1] \rightarrow \mathbb{R}$ be such that $f^{(2 n)}$ is absolutely continuous for some $n \geq 1$ and $\left(f^{(2 n+1)}\right)^{2} \in L_{1}[0,1]$. Then we have

$$
\begin{aligned}
& \left|\int_{0}^{1} f(t) d t-\frac{1}{8}\left[f(0)+3 f\left(\frac{1}{3}\right)+3 f\left(\frac{2}{3}\right)+f(1)\right]+T_{2 n}^{Q 4}\left(\frac{1}{3}\right)\right| \\
\leq & \frac{3}{8}\left[-\frac{1}{(4 n) !}\left(\frac{1}{18}+\frac{7}{2} 3^{-4 n}\right) B_{4 n}\right]^{\frac{1}{2}} \times\left(\int_{0}^{1} t(1-t)\left[f^{(2 n+1)}(t)\right]^{2} d t\right)^{\frac{1}{2}} .
\end{aligned}
$$

If $f^{(2 n+1)}$ is absolutely continuous for some $n \geq 0$ and $\left(f^{(2 n+2)}\right)^{2} \in L_{1}[0,1]$ we have

$$
\begin{aligned}
& \left|\int_{0}^{1} f(t) d t-\frac{1}{8}\left[f(0)+3 f\left(\frac{1}{3}\right)+3 f\left(\frac{2}{3}\right)+f(1)\right]+T_{2 n}^{Q 4}\left(\frac{1}{3}\right)\right| \\
\leq & \frac{3}{8}\left[\frac{1}{(4 n+2) !}\left(\frac{1}{18}+\frac{7}{2} 3^{-4 n-2}\right) B_{4 n+2}\right]^{\frac{1}{2}} \times\left(\int_{0}^{1} t(1-t)\left[f^{(2 n+2)}(t)\right]^{2} d t\right)^{\frac{1}{2}},
\end{aligned}
$$

where $T_{0}^{Q 4}\left(\frac{1}{3}\right)=T_{2}^{Q 4}\left(\frac{1}{3}\right)=0$ and

$$
T_{2 n}^{Q 4}\left(\frac{1}{3}\right)=\frac{1}{8} \sum_{k=2}^{n} \frac{\left(3^{2-2 k}-1\right) B_{2 k}}{(2 k) !}\left[f^{(2 k-1)}(1)-f^{(2 k-1)}(0)\right] .
$$

Remark 2.2: For $n=1$ in (2.8) if $f^{\prime \prime}$ is absolutely continuous and $\left(f^{\prime \prime \prime}\right)^{2} \in L_{1}[0,1]$ we get:

$$
\begin{aligned}
& \left|\int_{0}^{1} f(t) d t-\frac{1}{8}\left[f(0)+3 f\left(\frac{1}{3}\right)+3 f\left(\frac{2}{3}\right)+f(1)\right]\right| \\
\leq & \frac{1}{24 \sqrt{90}} \times\left(\int_{0}^{1} t(1-t)\left[f^{\prime \prime \prime}(t)\right]^{2} d t\right)^{\frac{1}{2}} .
\end{aligned}
$$

If $f^{\prime}$ is absolutely continuous, $\left(f^{\prime \prime}\right)^{2} \in L_{1}[0,1]$ and $n=0$ in (2.9) we have

$$
\begin{aligned}
& \left|\int_{0}^{1} f(t) d t-\frac{1}{8}\left[f(0)+3 f\left(\frac{1}{3}\right)+3 f\left(\frac{2}{3}\right)+f(1)\right]\right| \\
\leq & \frac{1}{8 \sqrt{3}} \times\left(\int_{0}^{1} t(1-t)\left[f^{\prime \prime}(t)\right]^{2} d t\right)^{\frac{1}{2}} .
\end{aligned}
$$

Corollary 3.3. Let $f:[0,1] \rightarrow \mathbb{R}$ be such that $f^{(2 n)}$ is absolutely continuous for some $n \geq 1$ and $\left(f^{(2 n+1)}\right)^{2} \in L_{1}[0,1]$. Then we have

$$
\begin{aligned}
& \left|\int_{0}^{1} f(t) d t-\frac{1}{6}\left[f(0)+4 f\left(\frac{1}{2}\right)+f(1)\right]+T_{2 n}^{Q 4}\left(\frac{1}{2}\right)\right| \\
\leq & \frac{1}{3}\left[-\frac{1}{(4 n) !}\left(\frac{1}{2}+2^{2-4 n}\right) B_{4 n}\right]^{\frac{1}{2}} \times\left(\int_{0}^{1} t(1-t)\left[f^{(2 n+1)}(t)\right]^{2} d t\right)^{\frac{1}{2}} .
\end{aligned}
$$


ČEBYŠEV FUNCTIONAL AND GENERAL FOUR-POINT QUADRATURE FORMULAE 75 If $f^{(2 n+1)}$ is absolutely continuous for some $n \geq 0$ and $\left(f^{(2 n+2)}\right)^{2} \in L_{1}[0,1]$ we have

$$
\begin{aligned}
& \left|\int_{0}^{1} f(t) d t-\frac{1}{6}\left[f(0)+4 f\left(\frac{1}{2}\right)+f(1)\right]+T_{2 n}^{Q 4}\left(\frac{1}{2}\right)\right| \\
\leq & \frac{1}{3}\left[\frac{1}{(4 n+2) !}\left(\frac{1}{2}+2^{-4 n}\right) B_{4 n+2}\right]^{\frac{1}{2}} \times\left(\int_{0}^{1} t(1-t)\left[f^{(2 n+2)}(t)\right]^{2} d t\right)^{\frac{1}{2}}
\end{aligned}
$$

where $T_{0}^{Q 4}\left(\frac{1}{2}\right)=T_{2}^{Q 4}\left(\frac{1}{2}\right)=0$ and

$$
T_{2 n}^{Q 4}\left(\frac{1}{2}\right)=\frac{1}{3} \sum_{k=2}^{n} \frac{\left(1-2^{2-2 k}\right) B_{2 k}}{(2 k) !}\left[f^{(2 k-1)}(1)-f^{(2 k-1)}(0)\right] .
$$

Remark 2.3: For $n=1$ in (2.10) if $f^{\prime \prime}$ is absolutely continuous and $\left(f^{\prime \prime \prime}\right)^{2} \in$ $L_{1}[0,1]$ we get:

$$
\left|\int_{0}^{1} f(t) d t-\frac{1}{6}\left[f(0)+4 f\left(\frac{1}{2}\right)+f(1)\right]\right| \leq \frac{1}{12 \sqrt{60}} \times\left(\int_{0}^{1} t(1-t)\left[f^{\prime \prime \prime}(t)\right]^{2} d t\right)^{\frac{1}{2}} .
$$

If $f^{\prime}$ is absolutely continuous, $\left(f^{\prime \prime}\right)^{2} \in L_{1}[0,1]$ and $n=0$ in $(2.11)$ we have

$$
\left|\int_{0}^{1} f(t) d t-\frac{1}{6}\left[f(0)+4 f\left(\frac{1}{2}\right)+f(1)\right]\right| \leq \frac{1}{6 \sqrt{2}} \times\left(\int_{0}^{1} t(1-t)\left[f^{\prime \prime}(t)\right]^{2} d t\right)^{\frac{1}{2}} .
$$

Corollary 3.4. Let $f:[0,1] \rightarrow \mathbb{R}$ be such that $f^{(2 n)}$ is absolutely continuous for some $n \geq 1$ and $\left(f^{(2 n+1)}\right)^{2} \in L_{1}[0,1]$. Then we have

$$
\begin{aligned}
& \left|\int_{0}^{1} f(t) d t-\left[f\left(-\frac{\sqrt{3}}{3}\right)+f\left(\frac{\sqrt{3}}{3}\right)\right]+T_{2 n}^{Q 4}\left(\frac{1}{2}-\frac{1}{2 \sqrt{3}}\right)\right| \\
\leq & \frac{1}{2}\left[-\frac{1}{(4 n) !}\left(B_{4 n}+B_{4 n}\left(\frac{\sqrt{3}}{3}\right)\right)\right]^{\frac{1}{2}} \times\left(\int_{0}^{1} t(1-t)\left[f^{(2 n+1)}(t)\right]^{2} d t\right)^{\frac{1}{2}} .
\end{aligned}
$$

If $f^{(2 n+1)}$ is absolutely continuous for some $n \geq 0$ and $\left(f^{(2 n+2)}\right)^{2} \in L_{1}[0,1]$ we have

$$
\begin{aligned}
& \left|\int_{0}^{1} f(t) d t-\left[f\left(-\frac{\sqrt{3}}{3}\right)+f\left(\frac{\sqrt{3}}{3}\right)\right]+T_{2 n}^{Q 4}\left(\frac{1}{2}-\frac{1}{2 \sqrt{3}}\right)\right| \\
& \leq \frac{1}{2}\left[\frac{1}{(4 n+2) !}\left(B_{4 n+2}+B_{4 n+2}\left(\frac{\sqrt{3}}{3}\right)\right)\right]^{\frac{1}{2}} \times\left(\int_{0}^{1} t(1-t)\left[f^{(2 n+2)}(t)\right]^{2} d t\right)^{\frac{1}{2}}
\end{aligned}
$$

where $T_{0}^{Q 4}\left(\frac{1}{2}-\frac{1}{2 \sqrt{3}}\right)=T_{2}^{Q 4}\left(\frac{1}{2}-\frac{1}{2 \sqrt{3}}\right)=0$ and

$$
T_{2 n}^{Q 4}\left(\frac{1}{2}-\frac{1}{2 \sqrt{3}}\right)=\sum_{k=2}^{n} \frac{2^{2 k}}{(2 k) !} B_{2 k}\left(\frac{3-\sqrt{3}}{6}\right)\left[f^{(2 k-1)}(1)-f^{(2 k-1)}(0)\right] .
$$


Remark 2.4: For $n=1$ in (2.12) if $f^{\prime \prime}$ is absolutely continuous and $\left(f^{\prime \prime \prime}\right)^{2} \in$ $L_{1}[0,1]$ we get:

$$
\begin{aligned}
& \left|\int_{0}^{1} f(t) d t-\left[f\left(-\frac{\sqrt{3}}{3}\right)+f\left(\frac{\sqrt{3}}{3}\right)\right]\right| \\
\leq & \frac{1}{4}\left[-\frac{17}{270}+\frac{1}{9 \sqrt{3}}\right]^{\frac{1}{2}} \times\left(\int_{0}^{1} t(1-t)\left[f^{\prime \prime \prime}(t)\right]^{2} d t\right)^{\frac{1}{2}} .
\end{aligned}
$$

If $f^{\prime}$ is absolutely continuous, $\left(f^{\prime \prime}\right)^{2} \in L_{1}[0,1]$ and $n=0$ in $(2.13)$ we have

$$
\begin{aligned}
& \left|\int_{0}^{1} f(t) d t-\left[f\left(-\frac{\sqrt{3}}{3}\right)+f\left(\frac{\sqrt{3}}{3}\right)\right]\right| \\
\leq & \frac{1}{8}\left[\frac{1}{3}-\frac{1}{2 \sqrt{3}}\right]^{\frac{1}{2}} \times\left(\int_{0}^{1} t(1-t)\left[f^{\prime \prime}(t)\right]^{2} d t\right)^{\frac{1}{2}} .
\end{aligned}
$$

The following Grüss type inequality also holds.

Theorem 4. Let $f:[0,1] \rightarrow \mathbb{R}$ be such that $f^{(2 n)}$ is absolutely continuous and $f^{(2 n+1)} \geq 0$ on $[0,1], n \geq 1$. Then we have the representation (2.1) and the remainder $T G_{2 n}(f)$ satisfies the bound

$$
\begin{aligned}
& \left|T G_{2 n}(f)\right| \leq \\
& \leq \frac{1}{2(2 n-1) !}\left\|G_{2 n-1}^{Q 4}(x, t)\right\|_{\infty}\left\{\frac{f^{(2 n-1)}(0)+f^{(2 n-1)}(1)}{2}-f^{(2 n-2)}[0,1]\right\} .
\end{aligned}
$$

Let $f^{(2 n+1)}$ is absolutely continuous and $f^{(2 n+2)} \geq 0$ on $[0,1], n \geq 0$. Then we have the representation (2.3) and the remainder $T G_{2 n+1}(f)$ satisfies the bound

$$
\begin{aligned}
& \left|T G_{2 n+1}(f)\right| \leq \\
& \leq \frac{1}{2(2 n) !}\left\|G_{2 n}^{Q 4}(x, t)\right\|_{\infty}\left\{\frac{f^{(2 n)}(0)+f^{(2 n)}(1)}{2}-f^{(2 n-1)}[0,1]\right\}
\end{aligned}
$$

for any $x \in(0,1 / 2]$ and

$$
f^{(k)}[0,1]=f^{(k)}(1)-f^{(k)}(0) .
$$

Proof. If we apply Theorem 2 for $f \rightarrow G_{2 n}^{Q 4}, g \rightarrow f^{(2 n)}$, we deduce

$$
\begin{aligned}
& \left|\int_{0}^{1} G_{2 n}^{Q 4}(x, t) f^{(2 n)}(t) d t-\int_{0}^{1} G_{2 n}^{Q 4}(x, t) d t \cdot \int_{0}^{1} f^{(2 n)}(t) d t\right| \\
\leq & \frac{2 n}{2}\left\|G_{2 n-1}^{Q 4}(x, t)\right\|_{\infty}\left(\int_{0}^{1} t(1-t) f^{(2 n+1)}(t) d t\right) .
\end{aligned}
$$

Since

$$
\begin{array}{r}
\int_{0}^{1} t(1-t) f^{(2 n+1)}(t) d t=\int_{0}^{1} f^{(2 n)}(t)[2 t-1] d t= \\
=\left[f^{(2 n-1)}(1)+f^{(2 n-1)}(0)\right]-2\left(f^{(2 n-2)}(1)-f^{(2 n-2)}(0)\right),
\end{array}
$$

using the representation (2.1) and the inequality (2.16), we deduce (2.14). 
Similarly, using the representation (2.3) we deduce (2.15).

\section{Aplications for Euler Bullen-Simpson's 3/8 FORMula}

For function $f:[0,1] \rightarrow \mathbb{R}$, with continuous fourth derivative $f^{(4)}$ on $[0,1]$ and $f^{(4)}(t) \geq 0, \forall t \in[0,1]$, we have

$$
\begin{aligned}
\frac{1}{8}\left[3 f\left(\frac{1}{6}\right)+2 f\left(\frac{1}{2}\right)+3 f\left(\frac{5}{6}\right)\right] & \leq \int_{0}^{1} f(t) d t \\
& \leq \frac{1}{8}\left[f(0)+3 f\left(\frac{1}{3}\right)+3 f\left(\frac{2}{3}\right)+f(1)\right]
\end{aligned}
$$

In the case when $f^{(4)}$ exists, the condition $f^{(4)}(t) \geq 0, \forall t \in[0,1]$ is equivalent to the requirement that $f$ is 4 -convex function on $[0,1]$. However, a function $f$ may be 4-convex although $f^{(4)}$ does not exist.

P. S. Bullen in [4] proved that, if $f$ is 4-convex, then (3.1) is valid. Moreover, he proved that the Maclaurin quadrature rule is more accurate than the Simpson's $3 / 8$ quadrature rule, that is we have

$$
\begin{aligned}
0 & \leq \int_{0}^{1} f(t) d t-\frac{1}{8}\left[3 f\left(\frac{1}{6}\right)+2 f\left(\frac{1}{2}\right)+3 f\left(\frac{5}{6}\right)\right] \\
& \leq \frac{1}{8}\left[f(0)+3 f\left(\frac{1}{3}\right)+3 f\left(\frac{2}{3}\right)+f(1)\right]-\int_{0}^{1} f(t) d t,
\end{aligned}
$$

provided $f$ is 4-convex. We shall call this inequality Bullen-Simpson's $3 / 8$ inequality.

In [8] the authors established a generalizations of the inequalities (3.1) and (3.2) for a class of $(2 r)$-convex functions and also to obtain some estimates for the absolute value of difference between the absolute value of error in the Maclaurin quadrature rule and the absolute value of error in the Simpson's 3/8 quadrature rule. Let us define

$$
\begin{aligned}
& D(0,1) \\
& :=\frac{1}{16}\left[f(0)+3 f\left(\frac{1}{6}\right)+3 f\left(\frac{1}{3}\right)+2 f\left(\frac{1}{2}\right)+3 f\left(\frac{2}{3}\right)+3 f\left(\frac{5}{6}\right)+f(1)\right] .
\end{aligned}
$$

We shall make use of the following seven-point quadrature formula

$$
\int_{0}^{1} f(t) d t \approx D(0,1)
$$

obtained by adding the Simpson $3 / 8$ and the Maclaurin quadrature formulae. It is suitable for our purposes to rewrite the second inequality in (3.2) in the form

$$
\int_{0}^{1} f(t) d t \leq D(0,1)
$$

As we mentioned earlier, this inequality is valid for any 4-convex function $f$ and we call it the Bullen-Simpson's 3/8 inequality. 
We consider the sequences of functions $\left(G_{k}(t)\right)_{k \geq 1}$ and $\left(F_{k}(t)\right)_{k \geq 1}$ defined by

$$
\begin{aligned}
G_{k}(t) & =2 B_{k}^{*}(1-t)+3 B_{k}^{*}\left(\frac{1}{6}-t\right)+3 B_{k}^{*}\left(\frac{1}{3}-t\right) \\
& +2 B_{k}^{*}\left(\frac{1}{2}-t\right)+3 B_{k}^{*}\left(\frac{2}{3}-t\right)+3 B_{k}^{*}\left(\frac{5}{6}-t\right), t \in \mathbb{R}
\end{aligned}
$$

and

where

$$
F_{k}(t)=G_{k}(t)-\tilde{B}_{k}, t \in \mathbb{R}
$$

$\tilde{B}_{k}=B_{k}(0)+3 B_{k}\left(\frac{1}{6}\right)+3 B_{k}\left(\frac{1}{3}\right)+2 B_{k}\left(\frac{1}{2}\right)+3 B_{k}\left(\frac{2}{3}\right)+3 B_{k}\left(\frac{5}{6}\right)+B_{k}(1)$.

For any function $f:[0,1] \rightarrow \mathbb{R}$ such that $f^{(n-1)}$ exists on $[0,1]$ for some $n \geq 1$ we define $T_{0}(f)=T_{1}(f):=0$ and

$$
T_{m}(f)=\frac{1}{8} \sum_{k=2}^{m} \frac{1}{(2 k) !} 2^{-2 k}\left(1-3^{2-2 k}\right) B_{2 k}\left[f^{(2 k-1)}(1)-f^{(2 k-1)}(0)\right] .
$$

In the next lemma the authors established the Euler Bullen-Simpson 3/8 formulae.

Lemma 1. Let $f:[0,1] \rightarrow \mathbb{R}$ be such that $f^{(n-1)}$ is a continuous function of bounded variation on $[0,1]$, for some $n \geq 1$. Then we have

$$
\int_{0}^{1} f(t) d t=D(0,1)+T_{r}(f)+\tau_{n}^{1}(f)
$$

where $r=[n / 2]$ and

$$
\tau_{n}^{1}(f)=\frac{1}{16(n !)} \int_{0}^{1} G_{n}(t) d f^{(n-1)}(t) .
$$

Also,

$$
\int_{0}^{1} f(t) d t=D(0,1)+T_{s}(f)+\tau_{n}^{2}(f)
$$

where $s=[(n-1) / 2]$ and

$$
\tau_{n}^{2}(f)=\frac{1}{16(n !)} \int_{0}^{1} F_{n}(t) d f^{(n-1)}(t) .
$$

Using Theorem 1 for identity (3.6) we get the following Grüss type inequality:

Theorem 5. Let $f:[0,1] \rightarrow \mathbb{R}$ be such that $f^{(n)}$ is absolutely continuous for some $n \geq 1$ and $\left(f^{(n+1)}\right)^{2} \in L_{1}[0,1]$. Then, we have

$$
\int_{0}^{1} f(t) d t-D(0,1)-T_{r}(f)=T G B_{n}(f)
$$

and the remainder $T G B_{n}(f)$ satisfies the estimations

$$
\left|T G B_{n}(f)\right| \leq \frac{1}{16}\left[\frac{2}{(2 n) !}\left(-21+43 \cdot 2^{-2 n}+63 \cdot 3^{-2 n}-63 \cdot 6^{-2 n}\right) B_{2 n}\right]^{\frac{1}{2}}
$$


ČEBYŠEV FUNCTIONAL AND GENERAL FOUR-POINT QUADRATURE FORMULAE 79

$$
\times\left(\int_{0}^{1} t(1-t)\left[f^{(n+1)}(t)\right]^{2} d t\right)^{\frac{1}{2}} .
$$

Proof. If we apply Theorem 1 for $f \rightarrow G_{n}, g \rightarrow f^{(n)}$, we deduce

$$
\begin{aligned}
& \left|\int_{0}^{1} G_{n}(t) f^{(n)}(t) d t-\int_{0}^{1} G_{n}(t) d t \cdot \int_{0}^{1} f^{(n)}(t) d t\right| \\
\leq & \frac{1}{\sqrt{2}}\left[T\left(G_{n}(\cdot), G_{n}(\cdot)\right)\right]^{\frac{1}{2}} \times\left(\int_{0}^{1} t(1-t)\left[f^{(n+1)}(t)\right]^{2} d t\right)^{\frac{1}{2}},
\end{aligned}
$$

where

$$
T\left(G_{n}(\cdot), G_{n}(\cdot)\right)=\int_{0}^{1}\left[G_{n}(t)\right]^{2} d t-\left[\int_{0}^{1} G_{n}(t) d t\right]^{2} .
$$

We get $\int_{0}^{1} G_{n}(t) d t=0$ and using integration by part we have

$$
\begin{aligned}
& \int_{0}^{1} G_{n}^{2}(t) d t=(-1)^{n-1} \frac{n(n-1) \ldots 2}{(n+1)(n+2) \ldots(2 n-1)}\left[\int_{0}^{1} G_{1}(t) G_{2 n-1}(t) d t\right] \\
= & (-1)^{n-1} \frac{(n !)^{2}}{(2 n) !}\left[-16 \int_{0}^{1} G_{2 n}(t) d t+4 G_{2 n}(0)+6 G_{2 n}\left(\frac{1}{6}\right)+6 G_{2 n}\left(\frac{1}{3}\right)\right] \\
= & (-1)^{n-1} \frac{(n !)^{2}}{(2 n) !}\left[44 B_{2 n}(t)+84 B_{2 n}\left(\frac{1}{6}\right)+84 B_{2 n}\left(\frac{1}{3}\right)+44 B_{2 n}\left(\frac{1}{2}\right)\right] .
\end{aligned}
$$

Using (3.6) and (3.10), we deduce the representation (3.8) and the bound (3.9).

Remark 3.1: Because of (3.4) we get

$$
\int_{0}^{1} F_{k}(t) d t=\int_{0}^{1} G_{k}(t) d t-\int_{0}^{1} \tilde{B}_{k} d t=-\tilde{B}_{k}
$$

and also

$$
\int_{0}^{1}\left[F_{k}(t)\right]^{2} d t=\int_{0}^{1}\left[G_{k}(t)\right]^{2} d t-2 \tilde{B}_{k} \int_{0}^{1} G_{k}(t) d t+\tilde{B}_{k}^{2} .
$$

So, using (3.7) similar as in (3.10), we deduce the representation (3.8) and the bound (3.9), too.

The following Grüss type inequality also holds.

Theorem 6. Let $f:[0,1] \rightarrow \mathbb{R}$ be such that $f^{(n)}$ is absolutely continuous and $f^{(n+1)} \geq 0$ on $[0,1]$. Then we have the representation (3.8) and the remainder $T G B_{n}(f)$ satisfies the bound

$$
\begin{aligned}
& \left|T G B_{n}(f)\right| \leq \\
& \frac{1}{2(n-1) !}\left\|G_{n-1}(t)\right\|_{\infty}\left\{\frac{f^{(n-1)}(0)+f^{(n-1)}(1)}{2}-f^{(n-2)}[0,1]\right\} .
\end{aligned}
$$

Proof. If we apply Theorem 2 for $f \rightarrow G_{n}, g \rightarrow f^{(n)}$, we deduce

$$
\left|\int_{0}^{1} G_{n}(t) f^{(n)}(t) d t-\int_{0}^{1} G_{n}(t) d t \cdot \int_{0}^{1} f^{(n)}(t) d t\right|
$$




$$
\leq \frac{n}{2}\left\|G_{n-1}(t)\right\|_{\infty}\left(\int_{0}^{1} t(1-t) f^{(n+1)}(t) d t\right) .
$$

So, similarly as in Theorem 4, using the representation (3.8) and the inequality (3.12), we deduce (3.11).

Remark 3.2: From [8] we have that for $n-1=2 k, k \geq 2$

$$
\left\|G_{n-1}(t)\right\|_{\infty}=\left\|G_{2 k}(t)\right\|_{\infty}=2^{1-2 k}\left(1-3^{2-2 k}\right)\left|B_{2 k}\right| .
$$

\section{REFERENCES}

[1] M. Abramowitz, I. A. Stegun (Eds), Handbook of mathematical functions with formulae, graphs and mathematical tables, National Bureau of Standards, Applied Math. Series 55, 4th printing, Washington 1965.

[2] A. Aglić Aljinović, A. Čivljak, S. Kovač, J. Pečarić, M. Ribičić Penava, General Integral Identities and Related Inequalities, Element, Zagreb, 2013.

[3] I. S. Berezin, N. P. Zhidkov, Computing methods, Vol. I, Pergamon Press, Oxford, 1965.

[4] P.S.Bullen, Error estimates for some elementary quadrature rules, Univ. Beograd Publ. Elektrotehn. Fak. Ser. Mat. Fiz., 602-633, (1978), 97-103.

[5] P. Cerone and S. S. Dragomir, Some new bounds for the Čebyšev functional in terms of the first derivative and applications, J. Math. Ineq. 8(1) (2014), 159-170.

[6] I.Franjić, J.Pečarić, I.Perić, General closed 4-point quadrature formulae of Euler type, Math. Inequal. Appl. 12(3) (2009), 573-586.

[7] I. Franjić, J. Pečarić, I. Perić, A. Vukelić, Euler integral identity, quadrature formulae and error estimations, Element, Zagreb, 2011.

[8] M. Matić, J. Pečarić, A. Vukelić, On generalization of Bullen-Simpson's 3/8 inequality, Math. Comput. Model. 41 (2005), 463-483.

Faculty of Science, University of Split,

Teslina 12, 21000 Zagreb, Croatia

E-mail address: milica@pmfst.hr

Faculty of Textile Technology, University of Zagreb,

Pierottijeva 6, 10000 Zagreb, Croatia

E-mail address: pecaric@element.hr

Department of Mathematics, Josip Juraj Strossmayer University of Osijek,

Trg Luudevita Gaja 6, 31000 Osijek, Croatia

E-mail address: mihaela@mathos.hr

Faculty of Food Technology and Biotechnology, University of Zagreb,

Pierottijeva 6, 10000 Zagreb, Croatia

E-mail address: avukelic@pbf.hr 